
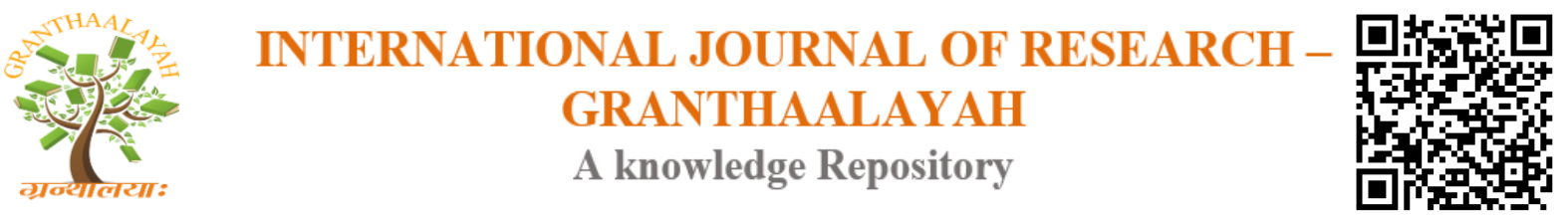

Social

\title{
EMPOWERING WOMEN THROUGH MOBILE AND WEB BASED APPLICATION TECHNOLOGY
}

\author{
Dr. R. Rajan ${ }^{1}$, G.Jayashri ${ }^{2}$ \\ ${ }^{1}$ Associate Professor, Formar Director, SRC, Chennai, Currently Associate Professor, \\ Department of Lifelong Learning, School of Education, Alagappa University, Karaikudi - \\ 630003 Tamil Nadu, India \\ ${ }^{2}$ Research Scholar, State Resource Centre, Affiliated to University of Madras, Chennai, India
}

\begin{abstract}
This paper recommends that there is an important role of Information Technology in the field of women empowerment such empowerment could easily be seen higher in the Urban and rural Tamil Nadu. There is high time for providing training for the women with the support of the administration for strengthening the National Computer literacy Mission. There must be the provision of allocation of budget and funding for testing conceptual framework at the grass root level to assess the effectiveness of empowering women through Information Technology. In India, women face enormous challenges with respect to health, education, and economic empowerment. For example, maternal mortality and malnutrition remain major problems, about third of women are unable to read and write, and economic opportunities are limited by pervasive discrimination and lack of access to market information. Mobile innovation is transforming lives for the better for women in a variety of ways across India. We recognize that the scaling of women-centered mobile programs and applications can only be achieved with improved financial, commercial, and marketing incentives and of course, cooperation. Thorough mobile application training we hope make a start - by financially supporting and recognizing innovative mobile and Web based applications and their potential in a public forum.
\end{abstract}

Keywords: Mobile Technology; Web Based Application; City Livelyhoodcentres; Empowering Women; Education; Motivation; Training.

Cite This Article: Dr. R. Rajan, and G.Jayashri. (2017). "EMPOWERING WOMEN THROUGH MOBILE AND WEB BASED APPLICATION TECHNOLOGY." International Journal of Research - Granthaalayah, 5(9:SE), 41-45. https://doi.org/10.5281/zenodo.1004550.

\section{Introduction}

Women are a great human resource in all countries and the role of women in society is critical for development. Arguably, making women strong is because to improve their decision making and control that affects their problems within the household and the society. There are many developing countries where women are not even listed in any citizen registration database, which 
makes it very difficult for them, especially the poorer ones in rural areas and of under-privileged class to assert social security, social protection, legacy, land etc. as there is practically no proof of their existence. Through their empowerment women gain greater share of control over resources - material, human and intellectual such as knowledge, information, ideas - and financial resources involving access to money and control over decision making in the home, community, society and nation. It leads them to become a critical and vital stakeholder among the human capital and their strategic presence in the society is widely accepted. The technology has provided many trends and filled the gap between education and employment opportunities for men as well women. As in the Worldwide the capacity of women to engage in the knowledge society is grossly underutilized. In the knowledge society they need access not only to new technologies but also to education, entrepreneurship and employment opportunities as well as the ability to participate fully in knowledge based activities. It is evident that rural India is contributing two-thirds of the total nation's population; thus, this heart of India requires heavy enforcement of prolific strategies, which could uplift the scenario of the nation as a whole. IT has become the chief determinant of the progress of nations, communities \& individuals. It is considered crucial that the improvements in our society benefit all citizens. No single group should be ignored or favored. The only way is "to make it better for all".

\section{Self Help Group}

Self-help group has become popular in rural parts of India. Most of the groups started small scale industries and delivering good quality goods / services to the consumers. Developing a web based information system about the SHG (Self Help Group) and providing more information about the various related details (i.e., training details, financial support, marketing, Government policies, etc.), will help other groups to communicate and enhance their business activity relevant to their expertise. Incorporating a Management Information System, tracking the progress and functions of the groups are some of the other important things where the IT applications can be very useful.

\section{Motivation Aspects}

In general women's are working oriented with lot of concentration, dedication, perfection and resulted oriented. Motivation is important for all kind of people, identifying the right people and motivating is an important thing. Normally they will be popularized in papers and magazines, this kind of information should also available in the Internet, which will enable International recognition to them. Women force comprises only a small percentage of the scientific and academic community barring teachers at the school and pre-school levels. But they have an attitude to work with sincerity and loyalty while keeping pace with the required timings, and given proper own space, they can play an increasingly important role in social, industrial and economic development of the country. As women involving equally as men, they can try to improve the livelihood among people as a long sustainable and by that campaigning the social and economic advancement of societies. Governments must design and implement national policies and programs that promote science and technology education for women and girls and which encourage women to enter into high value added ICT career. There exist some government projects for rural women education in Information Technology. 


\subsection{Potential}

As per Tamil Nadu Corporation for women Development (TNCWD) 500 CLCs are to be developed to assist the Urban Poor Livelihood Opportunities. City Livelihood Centers (CLC) have to register the services provided by the millions of urban poor and facilitate livelihood opportunity for them. In Tamilnadu, the cities have high potential for the services offered by Urban Poor. But channelizing the opportunities to urban poor is a great challenge.

As demonstrated in recent development in OLA Taxi, and Urban Clap etc. the development of mobile and web based application, channelizing the opportunities to urban poor will be easy and cost effective. Developing such mobile and web based application for Tamilnadu would help the CLCs to handle the services effectively.

\subsection{Sources for IT}

State Level Units of National Information Center (NIC) and Tamilnadu E - Governance Agency (TNeGA), are resourceful in helping TNCDW for development of Mobile and Web Based Applications. Besides these many IT firms are available in open market for entrusting works for developing web and mobile based applications by tender. We may utilize any of these for development of Mobile and Web Based Applications to support CLC. The exclusive servers of TNCDW or NIC servers can host and handle the data of the CLCs.

\subsection{Developing App and TOR for Apps}

The mobile and web based application may have following terms of reference while developing for the benefit of service provider and receiver.

- Geo mapping and tagging

- Registration of Parties

- Rating of the service

- Tracking of service

- E payment / Cashless
- Settlement of Bills online

- SMS service and Feedback

- Performance appraisal

- Service Standardization

- Pricing options to SP

Thus a centralized web and mobilize based application development is essential for effective functioning of CLCs. This may be developed with the help of NIC/ TNeGA /Private IT firms as decided by SMMU of NULM (TN).

\subsection{Demand and Supply of Urban Poor's Services}

Variety of services which are labour oriented and offered byurban poor has many perceived demands as follow:

- House maid services

- Plumbing / Electrical works

- Civil Labour / General Labour

- Sewage Repair / Cleaning
- Motor Repair

- Taxi/ Auto / Transport

- Catering

- Baby Care 
- Security services

- Marketing

- Tailoring Services
- Elderly Assistance

- Delivery of Goods

- Skilled Manpower

The Urban Poor are to be registered for the services offered in City Livelihood Centers. Such Registration may be around 2 million in Tamilnadu. Standardization of rates, certification and services offered is a main concern in service delivery through CLCs. Capacity building in this regard may be done for each CLC with the convergence of SSC, TNSDC and the Labour Department Schemes.

\subsection{Road Map for Support to CLCs:}

Following are the steps which may be followed for the development of support services to the CLCs:

- Developing TOR \& RFP for mobile and web services to be offered

- Identification of IT partner through RFP

- Agreement with IT partner(s) shortlisted for Apps

- Development of Mobile and Web based Application

- Creating linkages with Payment services

- Hosting them in Server(s) and Piloting

- Creating Infrastructure in CLCs for Apps

- Registering of Urban Poor Service Providers en masse

- Popularization of services of CLCs and client mobilization

- Delivery of Services through app facilitation

- Managing the web and Mobile assisted services of Poor in CLCs.

\section{Conclusion}

Women should be encouraged to bring their vision and leadership, knowledge and skills, views and aspirations into the development agenda from the grassroots to international levels and to make reachable to all women and others we are taking mobile phones and Web based Application as medium. Science and technology brings economic growth and well-being to people and it is not only the empowerment of women through science and technology, but also the enrichment of science and technology through women's participation. We just hope that women become empowered at $100 \%$ and become equal to men so that both of them may work side by side for a better world of today.

\section{References}

[1] “Mutram” Tamil Magazine from Jan'15 - Sep'17.

[2] Golden, S. A. R. (2016). Customers' Attitude Towards Online Shopping-An Analysis. International Journal of Business and Administration Research Review, 1(1), 453-455.

[3] Golden, S. A. R. (2017). Recent Research in Social Sciences \& Humanities. EduPedia Publications (P) Ltd.

[4] Golden, S. A. R., \& Regi, S. B. (2013). Mobile commerce in modern business era. International Journal of Current Research and Academic Review, 1(4), 96-102. 
[5] Golden, S. A. R. (2016). Mobile Subscribers' Satisfaction towards Offers. Shanlax International Journal of Arts, Science \& Humanities.

[6] June Lennie, "Including a diversity of rural women in a communication technology access project: Taking the macro and micro contexts into account", 5th Community Networking Conference, 3-5 July 2002, Monash University.

[7] M.S.Swaminathan, "Assessment of Impact of Information Technology on Rural Areas of India", International Development Research Center (IDRC), Canada.

[8] R. Rakesh, "Role of Information Technology in Women Empowerment", Global Journal of Finance and Management. Global Journal of Finance and Management, Vol. 2.

[9] Regi, S. B. (2016). Prospectus \& Challenges of Women Entrepreneurs-A Study with Special Reference to Tirunelveli District. International Journal of Scientific Research and Modern Education, 786, 792.

[10] Regi, S. B., \& Golden, S. A. R. (2014). A Study on Attitude of Employee towards Working Environment with Special Reference to RR Pvt Ltd. Review of Research, 2 (2), 1, 5.

[11] Regi, S. B., Golden, S. A. R., \& Franco, C. E. (2014). Role of Commercial Bank in the Growth of Micro and Small Enterprises. Golden Research Thoughts, 3 (7), 1, 5.

[12] Singh S.P., Biswas, P.K.,"An Overview of Changing Scenario of Women Empowerment in India's Five Year Plans: A Futuristic Vision of Eleventh Five Year Plan towards Women's Sustainability in Global Era' Paper presented in the National Seminar on Gender Budgeting and Women Empowerment", 2009.

[13] Website: http://www.tamilnadumahalir.org/document.html 